\title{
EL PROYECTO EMANCIPADOR DE LA PSICOLOGÍA DIALÉCTICA
}

\author{
Ricardo Oliveros M.*
}

\begin{abstract}
RESUMEN
En el texto El proyecto emancipador de la psicología dialéctica se presenta aspectos del desarrollo de la psicología dialéctica, como orientación teórico-conceptual y como modalidad de práctica profesional del psicólogo. Se exponen las formas de expresión de la psicología dialéctica, analizando y sintetizando puntos claves relacionados con la emancipación humana. Se trata de un esfuerzo por potenciar la ciencia psicológica con nuevos modelos, mejores estrategias e instrumentos más efectivos. Se plantea que el propósito de la psicología dialéctica es desarrollar un proyecto emancipador, como tarea abierta y perspectiva de futuro en el 50 aniversario de la psicología en el Perú.
\end{abstract}

Palabras clave: Psicología dialéctica, psicología integral, psicología para la liberación, proyecto emancipador, gestión de la realidad y gestión de la vida personal.

\begin{abstract}
In this paper aspects of the development of the dialectical psychology are presented as a theoretical-conceptual orientation and as a way of professional practice for psychologists. Ways of expression of dialectical psychology are expose, analyzing and synthesizing key points relating human emancipation. It's an effort for potentate the psychology science with new models, better strategies and more effective instruments. It's considered that the purpose of dialectical psychology is to develop an emancipator project, as an open task with future perspective in the 50th anniversary of psychology in Peru.
\end{abstract}

Keywords: Dialectical psychology, integral psychology, psychology for liberation, emancipate project, reality management and personal life management.

\section{INTRODUCCIÓN}

La psicología dialéctica, como orientación teórico-conceptual y como modalidad de la práctica profesional del psicólogo, especialmente en las condiciones de la globalización neoliberal, se desarrolla en el marco de un proyecto emancipador. En tal sentido, es

Docente de la Facultad de Psicología de la UNMSM. 
importante destacar algunos puntos claves relacionados con la historia de la psicología dialéctica, con las cuestiones centrales de la psicología dialéctica y con las perspectivas de la psicología dialéctica.

Así, en el texto El proyecto emancipador de la psicología dialéctica, se exponen las formas de expresión de la psicología dialéctica. En primer lugar, la psicología dialéctica como psicología integral, en la medida en que utiliza teóricamente categorías integradoras (actividad, conciencia, personalidad, comunicación). En segundo lugar, la psicología dialéctica como psicología para la liberación, en la medida en que asume y desarrolla un proyecto emancipador para las personas, contribuyendo activamente a la humanización de la sociedad.

Asimismo, en el texto El proyecto emancipador de la psicología dialéctica, se presentan orientaciones para potenciar la ciencia psicológica con nuevos modelos, mejores estrategias e instrumentos más efectivos de intervención profesional. En tal sentido, se abren nuevas perspectivas para el desarrollo de la psicología dialéctica. Por una parte, se destacan aspectos de la historia de la psicología dialéctica, valorando algunos hitos históricogeneracionales y sus respectivos aportes al proceso permanente de construcción de la psicología dialéctica. Por otra parte, pensando con perspectiva de futuro, en el 50 aniversario de la psicología en el Perú, se precisan los aportes más significativos a la psicología dialéctica y sus desarrollos posibles.

En tal sentido, la psicología dialéctica se desarrolla en el marco de un horizonte emancipador del ser humano como una propuesta integradora y liberadora de los conocimientos psicológicos, con una visión creativa del conocimiento-emancipación en función al desarrollo del ser humano, realizando un análisis crítico de la estructura y de la dinámica de las relaciones humanas en el contexto histórico-social y cultural.

También, la psicología dialéctica se desarrolla en el marco del paradigma crítico-constructivo de la gestión de la realidad y de la gestión de la vida personal, considerando la dinámica de desarrollo del contexto histórico-social y cultural, utilizando la metodología de la dialéctica materialista en las modalidades de síntesis teórica y de la sistematización de las prácticas.

Finalmente, la psicología dialéctica promueve un modelo de formación humana para la formación de los psicólogos emprendedores del siglo XXI, como líderes de desarrollo con un proyecto emancipador, como emprendedores sociales con visión de futuro especialmente en la dimensión cultural del desarrollo humano.

\section{ASPECTOS DE LA HISTORIA DE LA PSICOLOGÍA DIALÉCTICA}

Una revisión de la historia de la psicología dialéctica, como orientación teórico-conceptual en la investigación psicológica, nos permite visualizar puntos clave que nos explican las principales manifestaciones de su historia, tanto en la historia de la especialidad y en la trayectoria profesional de los psicólogos dialécticos.

Se trata de comprender, como una cuestión clave de la psicología dialéctica, las interrelaciones teóricas y prácticas entre una dialéctica de la situación como gestión de la realidad y una dialéctica de la persona como la gestión de la vida personal, asimilando de manera crítica y aplicando en forma creadora el planteamiento de Castilla del Pino (1968) ${ }^{1}$. Por tanto, es importante considerar los debates realizados sobre las diversas formulaciones en diversos contextos y escenarios: 
- La psicología dialéctica como psicología marxista.

- La psicología dialéctica como psicología científica.

- La psicología dialéctica como psicología materialista.

- La psicología dialéctica como psicología de orientación sociocultural e histórica.

$\mathrm{Al}$ respecto, se presenta una propuesta de modelo emancipatorio de la psicología dialéctica: La psicología dialéctica como paradigma revolucionario de las ciencias del psiquismo y de la personalidad.

Se propone un modelo emancipatorio que proporciona orientaciones estratégicas para la recuperación crítica de experiencias concretas y para la producción creadora de teorías científicas y modelos teóricos. Un modelo emancipatorio que posibilita la cualificación progresiva del conocimiento psicológico y potencia los esfuerzos orientados al desarrollo de las formas de expresión de la psicología dialéctica: como psicología integral y como psicologiá para la liberación

\section{CUESTIONES CENTRALES DE LA PSICOLOGÍA DIALÉCTICA}

Con el modelo emancipatorio de la psicología dialéctica, se comprende mejor el proceso de construcción de la psicología dialéctica desde la década del 50 hasta el año 2005, pues nos permite utilizar libremente la concepción piagetiana de la historia de la ciencia, denominamos marco histórico al conjunto de planteamientos fundamentales sobre la ciencia en una etapa determinada.

Así, al interior del marco histórico del proceso de producción de conocimientos de la psicología científica, se producen: Primero, el paradigma epistémico predominante, como forma de organización de la lógica teórica del proceso de integración de la psicología dialéctica; segundo, el paradigma social dominante, como modalidad de expresión de los condicionamientos sociales de la práctica científica de la psicología dialéctica.

Asimismo, el marco histórico determina las tareas principales del proceso construcción de la psicología científica, configurando las orientaciones principales para asumir como ejes de la integración-construcción al paradigma epistémico y al paradigma social de la psicología dialéctica.

(1) Paradigma epistémico de la psicología dialéctica.

El paradigma epistémico de una ciencia nos proporciona los determinantes teóricos del proceso de producción de conocimientos especializados mostrando las influencias principales de la ciencia en su desarrollo interno y destacando la contradicción fundamental en la lucha de tendencias en la ciencia en cuestión. La coyuntura teórica de la ciencia destaca la naturaleza fundamental de la lucha de tendencias en las modalidades y manifestaciones concretas que asume el paradigma epistémico. El paradigma epistémico se expresa como psicología integral, forma que asume la lógica de desarrollo teórico de la psicología dialéctica.

(2) Paradigma social de la psicología dialéctica.

El paradigma social de una ciencia señala los condicionamientos políticos, económicos y culturales del proceso de producción de conocimientos especializados mostrando la 
contradicción fundamental de la etapa y las contradicciones principales de las coyunturas específicas del proceso en cuestión.

Ahora bien, en el marco histórico de la producción de conocimientos de la ciencia psicológica y los ejes orientadores del proceso de integración-construcción de la psicología dialéctica, consideramos que la presente coyuntura científica y académica nos lleva a destacar como contradicción principal la lucha teórica, con un evidente transfondo ideológico, entre la "psicología cognitiva de la conducta" (un conductismo revitalizado por un cognitivismo restringido y mal empleado) y la psicología dialéctica (que asimila aportes significativos del cognitivismo social, enfoques innovadores de la psicología ecológica y planteamientos creativos de las corrientes liberadoras de la psicología dinámica). Al respecto, es importante destacar debates que invitan a la reflexión y al desarrollo de nuevos planteamientos, ampliando y profundizando en las propuestas existentes y en las propuestas actuales ${ }^{2}$. Sin embargo, se trata de debates académicos oficiales sobre los fundamentos de sus respectivas propuestas teóricas, sin profundizar en la tarea de transformar la realidad psicológica y socio-histórica.

En tal sentido, es importante comprender que la lucha de ideas se concentra en los diversos usos de la psicología en las prácticas sociales y en las diferentes orientaciones de la formación profesional del psicólogo en la etapa actual. Las connotaciones ideológicas y políticas de la lucha de ideas sobre la función social de la ciencia psicológica son evidentes y no pueden ser ni ocultadas ni postergadas por mucho tiempo más, tal como ha venido sucediendo por el paradigma social dominante, principalmente de orientación conductualcognitiva en unos casos y en otros con una orientación psicoanalítica y cognitiva.

Por lo señalado, acerca del modelo emancipatorio de la psicología dialéctica, como paradigma revolucionario en las ciencias del psiquismo y de la personalidad, en el paradigma social dominante, se destaca como característica básica la tergiversación y satanización del paradigma crítico-constructivo de la psicología dialéctica, sobre todo respecto a su expresión como psicología para la liberación.

$\mathrm{Al}$ respecto, consideramos que el desarrollo de nuevos planteamientos en la psicología dialéctica se debe asumir como una tarea teórica abierta y con perspectiva de futuro, pues la tarea de construcción de la psicología dialéctica se enmarca en el paradigma críticoconstructivo que se basa en la dialéctica materialista. Sobre todo si consideramos, con una perspectiva socio-histórica y cultural, la doble manifestación y expresión de la psicología dialéctica: como "psicología integral" y como "psicología para la liberación". Se trata de orientar el debate académico a la comprensión de la función social de la ciencia y de la profesión, profundizando la significación del modelo emancipatorio de la psicología dialéctica.

- La Psicología dialéctica como "psicología integral" desarrolla un enfoque sociocultural de las capacidades personales, trabajando sobre la base de categorías integradoras (actividad, conciencia, personalidad, comunicación).

- La Psicología como "psicología para la liberación" opera con una orientación liberadora de las capacidades personales, con cuestionamientos relacionados a la calidad de vida de la población, análisis crítico de las relaciones sociales y su expresión en los procesos de estructuración de estilos de vida saludables y en la configuración de las cualidades de la personalidad sana, con una actuación personal responsable personal e históricamente. 


\section{La dialéctica del amor y la psicología dialéctica}

Si consideramos la educación de los sentimientos como la base de la educación del ser humano, se destaca la importancia de los procesos de socialización y de personalización del ser humano en las condiciones complejas de la globalización neoliberal. También, se destaca de manera especial la dialéctica del amor con relación al modelo emancipatorio de la psicología dialéctica dentro del horizonte emancipador de los modelos de democratización y transformación de la realidad social.

Así, para comprender porque el tema del amor con sus problemas y conflictos es una cuestión omnipresente en la vida de las personas y, al mismo tiempo, un tema descuidado por la psicología académica, es necesario profundizar con una perspectiva socio-histórica y cultural en la dialéctica del amor, como una cuestión clave para la vida personal y para la transformación socio-histórica. Pero, sobre todo, es importante profundizar en el estudio de la dialéctica del amor, como cuestión cultural de importancia estratégica y como tema central de la psicología dialéctica, para asumir como desafío teórico la tarea de generar alternativas a la problemática de la relación amorosa y, simultáneamente, para asumir como desafío práctico la tarea de construir condiciones para la felicidad humana, en la dinámica concreta por definir la psicología del amor y de la felicidad como ejes de estructuración de la psicología dialéctica.

Ahora bien, concretamente, ¿qué se entiende por dialéctica del amor? ¿Existe "amor a la dialéctica"? ${ }^{3}$ Además, plantear la dialéctica del amor con un enfoque emprendedor de la creatividad personal ${ }^{4}$, exige la tarea de elaborar teóricamente con perspectiva socio-histórica y cultural las cuestiones claves del amor.

La dialéctica del amor, con relación a la tarea de construir las claves para una psicología dialéctica en el siglo XXI, como psicología del amor y como psicología de la felicidad humana, exige una aproximación multidimensional y concreta en base al modelo emancipatorio de la psicología dialéctica. Al respecto, la psicología de la persona concreta de Henri Wallón, es un ejemplo de esta orientación metodológica.

Réné Zazzo nos señala que Wallon, al mismo tiempo que pide a la juventud ser conscientes de la "deuda social" que tienen con relación a la formación que reciben, expresa su compromiso solidario y su vocación de estudio (ver recuadro, líneas más abajo). Así, destacando aspectos significativos de la vida y de la obra de Wallon, nos da indicaciones claves para el análisis psicológico de la dialéctica del amor en el proceso de construcción de la psicología dialéctica.

"A vosotros os corresponden los honores: y por qué, si no porque habéis tenido el privilegio de ir al liceo... Sin duda no os llega al liceo de la sociedad que trabaja para vosotros, más que un rumor lejano y de llamadas vagas... Intentemos ver esto con claridad; esforcémonos en ver sin ambigüedad las relaciones que no unen con los otros hombres... Vosotros no podéis ser aqui el continuo objeto de tanta solicitudy dedicación, no podéis retener ligados al cuidado de vuestro cuerpo y de vuestro espíritu a tantos trabajadores de todo tipo... no podéis absorber siempre sin restituir nada... Apresuraros a proclamar espontáneamente esta deuda social, mientras que aún podéis libremente hacerlo... Vivir para los otros, ¿no es desafiar la muerte oculta en el corazón del egoísmo?, ¿no está en eso toda nuestra independencia?"

Henri Wallon 5 . 
En tal sentido, destaca el interrogante que está en el centro de su obra científica walloniana y que, según Zazzo, va a transformar las perspectivas de la psicología: ¿cuál es la naturaleza de las relaciones que nos unen a otros hombres? ${ }^{6}$ Por tanto, destacamos como tema central del modelo emancipatorio de la psicología dialéctica la psicología del amor y la psicología de la felicidad humana, como cuestiones claves de la psicología dialéctica que sin dejar de lados los viejos debates sobre el objeto de estudio de la ciencia psicológica, aportan un cambio de perspectiva para el enfoque de los problemas psicológicos que es importante para poner el práctica el paradigma de la solidaridad en la construcción de una psicología para la liberación y para asumir el paradigma de la complejidad en la construcción de una psicología integral, como formas de expresión de la psicología dialéctica en el siglo XXI.

\section{PERSPECTIVAS DE LA PSICOLOGÍA DIALÉCTICA}

Las perspectivas de la psicología dialéctica, asumiendo los ejes de estructuración del modelo emancipatorio: Psicología integral y psicología para la liberación, son brillantes con relación a la práctica social del paradigma de la solidaridad (fundamentalmente, en el plano del paradigma social de la psicología dialéctica) y con el desarrollo teórico del paradigma de la complejidad (principalmente, en el plano del paradigma epistémico de la psicología dialéctica).

Al respecto, es fundamental enfatizar que en la psicología dialéctica, lo central está en el compromiso y la praxis. Especialmente, a través de la sistematización de las prácticas del trabajo profesional de los psicólogos dialécticos y mediante la síntesis teórica de los aportes significativos a la ciencia psicológica por la psicología dialéctica, es posible seguir desarrollando el modelo emancipatorio de la psicología dialéctica para el siglo XXI considerando los siguientes aspectos:

Primero, la temática de la formación del pensamiento psicológico con una perspectiva dialéctica e histórica es una tarea teórica que se tiene que desarrollar en colectivos de trabajo intelectual. La formación del pensamiento psicológico con perspectiva dialéctica e histórica se centra en la construcción de procesos de liberación humana y social, con prácticas de democratización social y de cambio cultural, promoviendo activamente las cualidades personales de los modelos de persona sana y las características de los estilos de vida saludable.

Segundo, la problemática del desarrollo humano genera una serie de tareas prácticas que la psicología dialéctica asume. Por una parte, se tiene que trabajar intensamente en la capitalización de experiencias de orientación personal y colectiva; por otra parte, se tiene que trabajar profundamente en la sistematización de prácticas profesionales, con una orientación centrada en la liberación humana y social.

\section{Núcleo de articulación y construcción de la Psicología dialéctica}

Con visión de futuro, con los ejes orientadores -psicología del amor y psicología de la felicidad humana- del proceso de estructuración del modelo emancipatorio de la psicología dialéctica, se asume como núcleo de la articulación y construcción de la "psicología dialéctica", al modelo teórico acerca de la estructura de la actividad consciente personal ${ }^{7}$, desarrollado por Pedro Ortiz Cabanillas. Es una tarea planteada que están trabajando varios 
grupos de profesionales y el equipo de profesionales que lo acompaña en su tarea profesional e investigadora. Al respecto, considerando sus aportes a las neurociencias en general y, específicamente, a las ciencias psicológicas, es importante destacar su explicación del ser humano como sistema informacional, su explicación del cerebro como sistema semiótico, su teoría del habla personal, etc ${ }^{8}$.

A nuestro parecer, el impacto de su proyecto intelectual en la actividad científica y profesional, especialmente de psicólogos y educadores, comienza con la publicación de El sistema de la personalidad (1994) y continúa con diversos textos sumamente importantes La formación de la personalidad (1997) y El nivel consciente de la memoria (1998) y sus Cuadernos de psicobiología: Introducción a una psicobiología del hombre (2000). Se trata de un impacto impresionante: Una verdadera revolución científica.

El texto Lenguaje y habla personal no solamente aporta significativamente al conocimiento científico, contribuye vitalmente a la formación de una nueva generación. Promueve la búsqueda de la verdad y de la justicia social, quiere que otros también busquen lo que el busca. Además, aspira que otros también desarrollen el conocimiento científico y ejerzan su actividad profesional al servicio de la liberación del ser humano, orientando el trabajo científico a mejorar la calidad de vida.

Una vez más, la psicología como ciencia obtiene su desarrollo por un científico y humanista que no es originalmente psicólogo de profesión. En esta oportunidad, el pensamiento teórico abre un nuevo paradigma, generando una alternativa al modelo colonizador en ciencia ${ }^{9}$ (de reproducción simple y de "validación" de aportes en el marco del positivismo psicométrico y conductual). La metodología de síntesis teórica ${ }^{10}$ nos invita a la realización de un nuevo tipo de estudios e investigaciones en el Perú.

Estamos ante un paradigma crítico-constructivo de orientación dialéctica ${ }^{11}$ : Una nueva perspectiva para la historia de la psicología en el Perú. El texto en cuestión abre una nueva etapa en el desarrollo de las teorías científicas que explican el lenguaje humano y, en tal sentido, invita a una actualización crítica de los conocimientos acerca del cerebro humano, especialmente de los conocimientos científicos relacionados con el habla personal. Así, teóricamente, la psicología como ciencia -en el Perú- ingresa al siglo XXI con un aporte teórico que invita a realizar esfuerzos colectivos en la misma dirección, una contribución decisiva para dinamizar y ampliar los espacios de discusión académica. Un punto de partida fundamental para la descolonización del conocimiento científico, para desarrollar teoría psicológica en el Perú. Asimismo, la Teoría del habla personal de Pedro Ortiz, invita a la reestructuración crítica de los conocimientos científicos acumulados, en el sentido de superación dialéctica.

\section{Situación sociocultural y gestión de la vida personal}

Una concepción dialéctica para la comprensión de la vida, implica formas de determinación funcional ${ }^{12}$ que relacionan experiencias y vivencias, ideas y razones, decisiones y actuaciones personales. Así, a nuestra vida llegan personas que se quedan para toda la vida en nuestro corazón y nos dejan la experiencia de un aprendizaje esencial: El aprendizaje de la convivencia personal humanizada. Y llegamos a sentir intensamente que la felicidad consiste en dar nuestra contribución al universo, participar activamente en la construcción de una sociedad humanizada, pletórica de amor y de solidaridad, contribuyendo activamente a que la vida sea mejor. 


\section{Un enfoque emprendedor de la creatividad personal}

Ahora bien, tanto los proyectos vitales como el diálogo creador como expresiones de un dinamismo sinérgico fundamental tienen complicaciones, problemas y conflictos ${ }^{13}$. Para comenzar, en un contexto de capitalismo salvaje y con la promoción abierta del individualismo neoliberal, ¿qué significa vivir bien la vida personal, qué exige el espíritu competitivo en un contexto de pobreza y desempleo abierto?

En la gestión de la vida personal, los esfuerzos para fortalecer la autonomía personal se enfrentan a dificultades prácticas de realización personal. Y los mejores deseos de amar y ser feliz confrontan las contradicciones de la vida personal, expresando los conflictos y crisis existenciales en la tarea de construcción del sentido de la vida personal en medio de condiciones adversas.

Ojalá todo fuera fácil en la gestión de la vida personal, pero la vida no es así. ¿Qué hacer para construir una sociedad humanizada y para que sea real la globalización de la solidaridad? ¿Por dónde empezar la lucha contra la alienación del capitalismo? ¿Cómo resistir y superar los procesos de despersonalización que promueve la infame propaganda del individualismo neoliberal?

Ahora bien, ¿cuál es la alternativa que brinda la psicología dialéctica como tendencia psicológica centrada en la dialéctica del amor y en la construcción de la felicidad humana? La alternativa es la propuesta de un enfoque emprendedor de la creatividad personal, un enfoque emprendedor para la gestión de las capacidades y competencias personales.

\section{Contra la alienación y la despersonalización}

Al respecto, es clave preguntar: ¿Qué respuesta implica el enfoque emprendedor a la realidad de la alienación capitalista? ¿Cómo confronta la creatividad personal al proceso de despersonalización del individualismo neoliberal? Se trata de una propuesta para cambiar la vida y de un programa para construir un contexto de humanización con el paradigma de la solidaridad.

Se trata comprender las expresiones de la alienación del sistema capitalista, con su correlato de despersonalización en la gestión de la vida personal. Se trata de emprender la lucha por condiciones favorables para el desarrollo humano, asumiendo que un estilo solidario de vida personal se centra en la autonomía personal y se expresa en los esfuerzos de realización humana.

\section{CONCLUSIONES}

1. La Psicología dialéctica es un paradigma crítico-constructivo en las ciencias del psiquismo y de la personalidad. Se confronta con el paradigma positivista-conductual en la explicación científica y en la gestión del conocimiento científico.

2. La Psicología dialéctica tiene doble expresión, como psicología integral y como psicología para la liberación, en el marco de un horizonte emancipador para el desarrollo de las capacidades del ser humano.

3. La Psicología dialéctica como psicología integral, el plano teórico-metodológico, supera los enfoques unilaterales de las tendencias psicológicas con un trabajo de integración categorial. 
4. La Psicología dialéctica define con claridad y precisión el objeto de estudio y la tarea fundamental de la psicología científica. Por ejemplo, como lo hace Galperin con un enfoque dialéctico centrado en la actividad orientadora.

5. La Psicología dialéctica como psicología para la liberación toma como eje crítico las condiciones socioculturales de desarrollo psicológico y aporta estrategias liberadoras para el progreso psicológico de individuos y organizaciones.

6. La Psicología dialéctica lucha para evitar la existencia de personas sometidas a niveles de sobrevivencia psíquica, rechaza las estrategias orientadas al agostamiento psíquico de las masas y combate la lógica de embrutecimiento espiritual del pueblo.

7. La Psicología dialéctica, en el marco de un proyecto emancipador orientado al desarrollo del potencial humano, aporta a la democratización de la sociedad con un modelo emancipatorio para la gestión de la vida personal.

8. La Psicología dialéctica explica la estructura y dinámica de la actividad personal, con un enfoque integral y liberador. El modelo emancipatorio de la psicología dialéctica es funcional a la gestión del saber y a la gestión de la vida personal.

9. La Psicología dialéctica se confronta principalmente con la "psicología cognitiva de la conducta", en la explicación de principios para la gestión de la vida personal y en el desarrollo de principios para la efectividad de la actuación personal.

10. Enfoque emprendedor de la creatividad personal. Se trata de una orientación en la gestión de la vida personal que se centra en la gestión de las capacidades personales con un modelo y estilo emprendedor de la actuación personal.

11. La Psicología dialéctica es un paradigma crítico-constructivo del conocimiento psicológico y un paradigma revolucionario en las ciencias psicológicas que lucha contra la alienación y la despersonalización del ser humano.

12. La Psicología dialéctica tiene como núcleo de articulación y construcción, para orientar el proceso su proceso de desarrollo, al modelo teórico acerca de la estructura de la actividad consciente personal desarrollado por Pedro Ortiz Cabanillas.

\section{REFRENCIAS BIBLIOGRÁFICAS}

1. Castilla del Pino, Carlos (1975). Dialéctica de la personalidad, Dialéctica de la situación. Barcelona: Ediciones Península.

2. Galperin, P. Y. (1979). Introducción a la psicología (Un enfoque dialéctico). España: Editorial Pablo del Río.

3. Oliveros Mejía, Ricardo (1989). Fundamentos de psicología dialéctica. Texto inédito.

4. Oliveros Mejía, Ricardo y Ramos Flores, María Teresa (1999). Educación y desarrollo personal. UNMSM.

5. Oliveros Mejía, Ricardo (2004). Perspectiva emprendedora del cambio educativo. Editorial Bruño.

6. Ortiz Cabanillas, Pedro (1994). El sistema de la personalidad. Ed. Orión. 
7. Ortiz Cabanillas, Pedro (2002). Lenguaje y habla personal. Perú: Fondo Editorial de la UNMSM.

8. Ortiz Cabanillas, Pedro (1994). La formación de la personalidad (1997).

9. Ortiz Cabanillas, Pedro (1994). El nivel consciente de la memoria (1998). Fondo Editorial Universidad de Lima.

10. Piaget, Jean; René Zazzo; y otros (1971). Debates sobre psicología, filosofía y marxismo. Argentina: Editorial Amorrortu.

11. Riviere, Angel. (1988). La psicología de Vigotsky. Editorial Aprendizaje-Visor.

12. Seve, Lucien (1972). Marxismo y Teoría de la Personalidad. Argentina: Editorial Amorrortu.

13. Thénon, Jorge (1974). Psicología dialéctica. Argentina: Editorial Paidós.

14. Wallon, Henri (1981). Psicología del niño. Pablo del Río Editor.

15. Yaroshevsky, Mijaíl (1979). La psicología en el siglo XX. Editorial Grijalbo.

16. Zazzo, René.(1976). Psicología y marxismo (La vida y la obra de Henri Wallon). España: Pablo del Río Editor.

\section{Notas}

1 Castilla del Pino, Carlos. (1975)Dialéctica de la personalidal, Dialéctica de la situación. Barcelona: Ediciones Península.

2 Es importante destacar el debate actual entre psicoanalistas y conductistas alrededor del polémico texto El libro negro del psicoanálisis de Mikkel Borch-Jacobsen.

3 Evidentemente, la profesión de fe y compromiso para con la dialéctica deben superar el nivel de aprendizaje de recetas, para desarrollar un modo de pensamiento y razonamiento dialéctico.

4 La creatividad personal como noción orientadora es funcional al diseño de un programa de vida y de actividad personal. Y un enfoque emprendedor de la creatividad personal se orienta al diseño de un modo y un estilo emprendedor en la gestión de la vida personal.

5 Citado por Réné Zazzo (1976) en Psicología y marxismo (La vida y la obra de Henri Wallon), Pablo del Rio Editor, España.

6 Orígenes y actualidad del pensamiento de Henri Wallon, en Réné Zazzo (1976): Psicología y marxismo (La vida y la obra de Henri Wallon), Pablo del Río Editor, España.

7 Se tiene que profundizar en la explicación y comprensión del Modelo teórico de la estructura de la actividad consciente personal de Pedro Ortiz Cabanillas.

8 Ortiz Cabanillas, Pedro. (2002) Lenguaje y habla personal Perú: Fondo Editorial de la UNMSM.

9 El aporte más significativo para lo que denominó «modelo colonizador en ciencia», está en los planteamientos de Aníbal Quijano acerca de la colonialidad del saber.

10 La metodología de síntesis teórica la plantea -en el plano científico y epistemológico- Kedrov.

11 El paradigma crítico-constructivo como alternativa al paradigma positivista-conductual. Para explicar el conocimiento científico y para la crítica al modelo colonial de hacer ciencia en el Perú.

12 En la psicología dialéctica, el desarrollo de los procesos complejos de la vida personal se interpreta y explica mediante relaciones de determinación funcional en el cuadro de la dialéctica materialista.

${ }^{13}$ Los proyectos vitales fundamentan una educación para la autonomía personal y el diálogo creador expresa las posibilidades constructivas de las relaciones interpersonales. El dinamismo sinérgico es la fuente que alimenta el paradigma de la solidaridad humana, expresando la fuerza constructiva de la fe y la fuerza movilizadora del amor en las relaciones interpersonales. 